\title{
Childhood renal tumors: surgical treatment and results
}

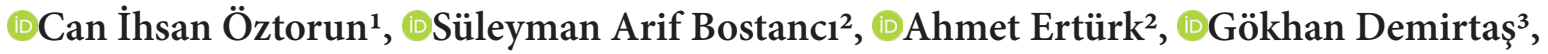

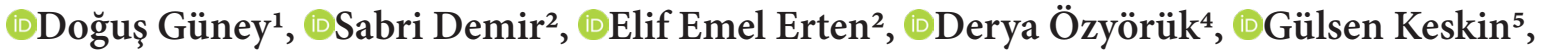

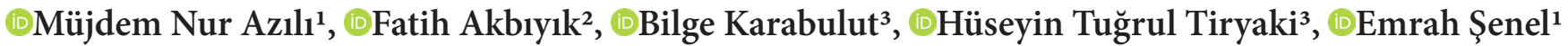 \\ ${ }^{1}$ Ankara Yildırım Beyazit University, Faculty of Medicine, Department of Pediatric Surgery, Ankara, Turkey \\ ${ }^{2}$ Ankara City Hospital, Children's Hospital, Department of Pediatric Surgery, Ankara, Turkey \\ ${ }^{3}$ Ankara City Hospital, Children's Hospital, Department of Pediatric Urology, Ankara, Turkey \\ ${ }^{4}$ Ankara City Hospital, Children's Hospital, Department of Pediatric Oncology, Ankara, Turkey \\ ${ }^{5}$ Ankara Dışkapı Yıldırım Beyazıt Hospital, Children’s Hospital, Department of Pediatric Anesthesiology, Ankara, Turkey
}

Cite this article as: Öztorun Cİ, Bostancı SA, Ertürk A, et al. Childhood renal tumors: surgical treatment and results. Anatolian Curr Med J 2022; 4(1); 76-80.

\begin{abstract}
Aim: Renal tumors in children are rare. Wilms' tumor (WT) is the most common renal tumor in childhood. The aim of this study is to investigate the data on the demographic factors, treatment, and follow-up results of pediatric patients who were operated on for renal tumors and determine the factors affecting mortality.

Material and Method: Patients who were operated for renal tumor in our clinic in 2005-2020 were evaluated retrospectively. Age at diagnosis, gender, complaint, localization of the involved kidney, additional anomalies, tumor size, tru-cut biopsy performed, tumor stage, distant metastasis, applied treatments, pathology, treatment complications, and follow-up period were examined.

Results: Of the 47 patients, 25 were female and 22 were male. The mean age was $45.46(2-204)$ months. The tumor was located in the right in 21 cases, left in 23 cases and bilateral in three cases. The mean length of the tumor was $11.73 \mathrm{~cm}$. At the time of diagnosis, there was metastasis in 15 cases (31.9\%). While metastasis were the most common seen in lung (24.3\%), bone-cell metastases were seen in clear cell carcinoma (33.3\%) and brain metastases were seen in rhabdoid tumor (50\%). Tru-cut biopsy was performed in 15 (31.9\%) cases and biopsy was diagnostic in ten cases. Histopathologically, 41 cases had WT (87.23\%), three cases were clear cell carcinoma (6.3\%), two cases had anaplasia rhabdoid tumor (4.2\%), and one case had metanephric adenoma. Relaps occured in nine cases (19.14\%) during the follow-up period. Histopathologically, one case was a clear cell carcinoma, one case was a rhabdoid tumor, and seven cases were unilateral WT. The survival rate of our series was $89,4 \%$.

Conclusion: The most common renal tumor in childhood was WT. Surgery have no effect on survival; the most important survival factors were detecting the existence of rhabdoid tumors and anaplasia histopathologically. Therefore, during the followup and treatment of renal tumors in childhood, pathological examination should be of primary importance and followed up with the pediatric oncologists.
\end{abstract}

Keywords: Renal tumors, children, surgery, Wilms tumor, rhabdoid tumor, clear cell carcinoma

\section{INTRODUCTION}

Renal tumors in children constitute 6-7\% of all childhood tumors and are rare. Such tumors are usually detected incidentally when the child is bathed by the parent when the mass is palped or during routine physical examination or screening of children with known clinical syndromes predisposed to renal disease (1). Wilms' tumor (WT) is the most common renal tumor in childhood. Also, WT is the second most common intra-abdominal solid tumor after neuroblastoma in children. The mean age of diagnosis of WT is around 3 years; it is common in children aged 1-4 years old (2). Other renal tumors are clear cell sarcoma of the kidney, congenital mesoblastic nephroma, cystic partially differentiated nephroblastoma, malignant rhabdoid tumor (MRT), renal cell carcinoma, renal medullary carcinoma, intrarenal neuroblastoma, and renal lymphoma (3). Although non-WT kidney tumors constitute $10 \%$ of childhood renal tumors, they have higher morbidity and mortality rates than WT (4). There is debate on and differences in the follow-up and treatment of these rare and heterogeneous tumors. For example, while cystic tumors have a good prognosis, malignant rhabdoid tumors have an aggressive course. 
This study aimed to investigate the data on the demographic factors, treatment, and follow-up results of pediatric patients who were operated on for renal tumors and determine the factors affecting mortality.

\section{MATERIAL AND METHOD}

This study was approved by the 2. Clinical Researchs Ethics Committee of Ankara City Hospital, under number E2-21-436 and 10/13/2021 dated. All procedures were performed adhered to the ethical rules and the Helsinki Declaration of Principles. Data on 50 children who were treated for renal tumors at in our hospital between January 2005-January 2020 were retrospectively analyzed from the hospital computer records and files. Three cases were excluded from the study because they were operated on in another hospital. The cases were evaluated in terms of age at diagnosis, gender, complaint, localization of the involved kidney, additional anomalies, tumor size, trucut biopsy performed, tumor stage, distant metastasis, applied treatments, pathology, treatment complications, and follow-up period. In all cases; tru-cut biopsy, neoadjuvant chemotherapy, timing of surgery, and subsequent treatment requirement were decided within TPOG protocols in the pediatric oncology council, which consists of a pediatric surgeon-oncologistradiologist-radiation oncologist, and pathologist.

\section{RESULTS}

A total of 47 children, 25 girls and 22 boys, who were operated on in our clinic for renal tumors were included in the study. The mean age of diagnosis of the cases was 45.46 (2-204) months. The mean age at diagnosis of the 41 patients with WT was 48.8 (2-204) months. The mean age of those with non-WT was 34 (4-60) months. The tumors were located on the left side in 23 cases, on the right in 21 cases, and bilaterally in three cases. Congenital anomalies, including Beckwith-Wiedeman syndrome (in one case), Ochoa syndrome (one case), and chromosomal breakage syndrome (one case), were detected.

The oncology council decided to perform a tru-cut biopsy for diagnosis in $15(31,9 \%)$ of the cases. The tru-cut biopsy results were reported as consistent with necrosis in five cases, diagnostic in ten cases, WT in eight cases, clear cell carcinoma in one case, and rhabdoid tumor in one case. Based on the treatment plans of the oncology council, surgery was performed in 32 (68.08\%) cases after neoadjuvant chemotherapy while surgery was performed initially in $15(31,9 \%)$ cases. Neoadjuvant chemotherapy procedure was vincristine and dactinomycin for 4 weeks in patients without metastasis, and vincristine, dactinomycin and doxorubicin for 6 weeks in patients with metastasis. Total nephroureterectomy was performed in 38 cases with unilateral tumors; Lymph node dissection was performed in 12 cases. The mean length of the tumor was $11.73 \mathrm{~cm}(4-20 \mathrm{~cm})$. The dimensions of bilaterally located tumors and the surgery performed are also shown (Table 1).

The most common tumor was WT with 41 cases. Other pathological diagnoses were clear cell carcinoma in three cases, rhabdoid tumor in two cases, and metanephric adenoma in one case. Anaplasia was observed in five patients with WT (Table 2).

The pathology results showed favorable histology in 37 cases $(78.72 \%)$ and unfavorable histology in 10 cases $(21.27 \%)$. Distant metastases were detected in 15 cases (27.6\%) at time of diagnosis and the cases were considered as stage IV according to the TPOG staging. The organs with metastases and their pathological diagnoses are shown in Table 3.

\begin{tabular}{|c|c|c|c|c|c|}
\hline $\begin{array}{l}\text { Bilateral Wilms' } \\
\text { Tumor Case }\end{array}$ & Tumor size $(\mathrm{cm})$ & $\begin{array}{l}\text { Neodajuvant } \\
\text { chemotherapy }\end{array}$ & $\begin{array}{l}\text { Distant } \\
\text { metastasisorgan }\end{array}$ & Surgery & Follow-up \\
\hline $\begin{array}{l}\text { First Case } \\
\text { One- year-old girl }\end{array}$ & $\begin{array}{l}\text { Right: } 9 \mathrm{~cm} \\
\text { Left: } 4.5 \mathrm{~cm}\end{array}$ & Performed & None & Bilateral mass excision & $\begin{array}{l}6 \text { month CT RT } \\
\text { Recovered }\end{array}$ \\
\hline $\begin{array}{l}\text { Second Case } \\
3 \text {-year- old boy }\end{array}$ & $\begin{array}{l}\text { Right: } 3.5 \mathrm{~cm} \\
\text { Left: } 7.5 \mathrm{~cm}\end{array}$ & Performed & Lung & $\begin{array}{l}\text { Right kidney } \\
\text { Mass excision } \\
\text { Left kidney total nephrectomy }\end{array}$ & $\begin{array}{l}6 \text { month CT RT } \\
\text { Recovered }\end{array}$ \\
\hline $\begin{array}{l}\text { Third Case } \\
\text { 3.5-year-old girl }\end{array}$ & $\begin{array}{l}\text { Right: } 1.5 \mathrm{~cm} \\
\text { Left: } 10 \mathrm{~cm}\end{array}$ & Performed & None & $\begin{array}{l}\text { Right kidney wedge resection } \\
\text { Left kidney } \\
\text { Total nephrectomy }\end{array}$ & $\begin{array}{l}6 \text { month CT RT } \\
\text { Relapse }\end{array}$ \\
\hline
\end{tabular}

Table 2. The mortality according to histopathological diagnoses

\begin{tabular}{|c|c|c|c|c|c|c|}
\hline Tumor & n (\%) & Mean age & G/B & Recover & Relapse & Ex \\
\hline Wilms tumor & $41(87.23 \%)$ & 4.06 years & $21 / 20$ & 34 & 7 & $3(7.3 \%)$ \\
\hline Clear cell carcinoma & $3(6.38 \%)$ & 2.8 years & $2 / 1$ & 1 & 1 & - \\
\hline Rhabdoid tumor & $2(4.25 \%)$ & 0.9 years & $2 / 0$ & - & 1 & $2(100 \%)$ \\
\hline Metanephric adenoma & $1(2.12 \%)$ & 1.25 years & $0 / 1$ & 1 & - & - \\
\hline Total & 47 & 3.78 years & $25 / 22$ & $36(76.5 \%)$ & $9(19.1 \%)$ & $5(10.6 \%)$ \\
\hline
\end{tabular}




\begin{tabular}{|c|c|c|}
\hline $\begin{array}{l}\text { Pathological } \\
\text { diagnosis }\end{array}$ & Distant metastasis & Tumor stage \\
\hline $\begin{array}{l}\text { Wilms' tumor } \\
(\mathrm{n}=41)\end{array}$ & $\begin{array}{l}\text { Lung }(\mathrm{n}=10) \\
\text { Lung and Liver }(\mathrm{n}=2) \\
\text { Brain }(\mathrm{n}=1)\end{array}$ & $\begin{array}{l}\text { Stage I: } 7 \text { patient }(17.07 \%) \\
\text { Stage II: } 16 \text { patient }(39.02 \%) \\
\text { Stage III: } 4 \text { patient }(9.7 \%) \\
\text { Stage IV: } 10 \text { patient }(24.3 \%) \\
\text { Stage V: } 4 \text { patient }(9.7 \%)\end{array}$ \\
\hline $\begin{array}{l}\text { Clear Cell } \\
\text { Carcinoma } \\
(\mathrm{n}=3)\end{array}$ & Bone $(n=1)$ & $\begin{array}{l}\text { Stage I: } 0 \\
\text { Stage II: } 1 \text { patient }(33.3 \%) \\
\text { Stage III: } 1 \text { patient }(33.3 \%) \\
\text { Stage IV: } 1 \text { patient }(33.3 \%)\end{array}$ \\
\hline $\begin{array}{l}\text { Rhabdoid } \\
\text { tumor }(n=2)\end{array}$ & Brain and Lung $(\mathrm{n}=1)$ & $\begin{array}{l}\text { Stage III: } 1 \text { patient } \\
\text { Stage IV: } 1 \text { patient }\end{array}$ \\
\hline Metanephric a & Idenoma $(\mathrm{n}=1)$ & Stage 1: 1 patient \\
\hline
\end{tabular}

While the most common lung metastasis $(24,3 \%)$ was seen in WTs, bone metastasis (33.3\%) was evident in clear cell carcinoma, while lung and combined brain metastasis were evident in rhabdoid tumors (50\%).

Bilateral WT were detected in three cases. Demographic data, treatments, histopathological diagnoses, and follow-up processes of the cases are shown in the table 1. The mean age of patients with bilateral WT was 2.5 (1-3.5) years; two females (66\%) and one male (33\%).

The mean follow-up period of the cases was 48 (4-65) months. During the follow-up period, relapse developed in nine cases (19.14\%). Histopathologically, one case was a clear cell carcinoma, one case was a rhabdoid tumor, and seven cases were unilateral WT. Six cases were unfavorable and three cases were favorable. In the treatment of relapsed tumors, reoperation and excision of the mass were performed in five cases. Chemotherapy was performed in four cases. Three (33.3\%) of the patients died in the treatment process.

Chemotherapy was performed in the cases for an average of 7.8 (4-12) months post-op. In the postoperative period, $40 \%$ of the cases were administrated Vincristine + Actinomycin-D + Doxurabucin, $60 \%$ of them were administrated Vincristine + Actinomycin. Radiotherapy was administered in addition to post-op chemotherapy in 20 cases.

Five patients died in our study. Two had rhabdoid tumors, two had stage IV anaplasic WT, and the other had a stage III relapsed WT. The mortality rates according to histopathological diagnoses are shown in Table 2. The 5-year surveillance of the cases in our series was $89.3 \%$.

\section{DISCUSSION}

Renal tumors are among the most common malignant solid tumors in children, accounting for $5 \%-6 \%$ of all malignant childhood tumors, with WT being the most common renal malignancy (5). In this study, as per the literature, we observed that $87.23 \%$ of our cases received a diagnosis of WT, followed by clear cell sarcoma of the kidney (CCSK) (6.38\%), malignant rhabdoid tumor of the kidney (MRT) (4.25\%), and metanephric adeoma (2.12\%).

In the literature, synchronous or metachronous bilateral WT rate was reported as $5-10 \%$ of children with WT (6). In our study, bilateral synchronous WT were detected at a rate of $8.5 \%$, which was in accordance with the literature.

While renal tumors are common in boys in European studies, they are also frequently seen in girls in National Wilms Tumor Study Group (NWTS) (7). In our study, we found that the female/male ratio was 1.13:1. In the National WT study of the Turkish Pediatric Oncology Group (TPOG), the median age of patients was 3 years (8). The mean age at diagnosis of the patients in our study was 45.84 months (2-204 months). The mean age at diagnosis of 38 patients with WT was 48.8 months (2204 months). The mean age of non-WT patients was 25 months (4-60 months). Although it has been reported in the literature that the mean age of non-WT patients tends to be higher, the mean age of patients with a diagnosis of WT was found to be statistically higher than those with a diagnosis of non-WT in our study. (p=0.04) (9) (10).

WAGR (WT, aniridia, genitourinary anomalies, and mental retardation), Denys-Drash syndrome, and Beckwith-Wiedemann syndrome may be associated in 5-10\% of cases with WT (11) (12). In our study, one patient with WT (2.6\%) had Beckwith-Wiedemann syndrome. Also, we observed one case of Ochoa syndrome, which was seen for the first time in the literature and previously reported by Emir et al. (13), and one case of chromosomal breakage syndromes (WT together with hepatocellular carcinoma).

Different methods are preferred in Europe and America for the treatment of childhood renal tumors. While preoperative chemotherapy is preferred by The International Society of Paediatric Oncology (SIOP) protocol in Europe, initial surgery followed by chemotherapy are prefered by the COG protocol in the USA. The aim of pre-surgical chemotherapy in SIOP is to prevent the spread of peritoneal cancer and reduce the stage of the disease (14). No differences in the overall survival rates for the SIOP and COG approaches were evident (15). In our study, the SIOP protocol was applied to 32 cases $(68.08 \%)$ by performing a tru-cut biopsy and pre-op chemotherapy, while the COG protocol was applied to 15 cases (31.9\%) by performing surgery first.

In bilateral WT patients, preoperative chemotherapy has the advantage of reducing tumor volume, and the treatment response may provide a valuable prognostic indicator. (16) In our study, in accordance with the literature, neoadjuvant chemotherapy was given to all patients with bilateral WT. 
The standard surgery in the SIOP and COG protocols for WT is open nephrectomy, whereas nephron-sparing surgery (NSS) has been recommended as the treatment of choice for bilateral WT (17). In our study, total open nephroureterectomy was performed in 38 cases. Lymph node dissection was performed in 12 cases. In two of the bilateral cases, NSS was performed on one kidney and total ureterenephrectomy on the other kidney. Bilateral NSS was performed in one case.

In developed countries, with the development of multimodal surgery, chemotherapy, and radiotherapy treatments for childhood kidney tumors, survival rates have increased up to $90 \%$ (7). Although most patients with WT survive, patients with relapsed and anaplastic histology WT have poor survival rates; fewer than 15\% achieve durable survival (18).

Anaplasia is defined by the presence of polyploid atypical mitotic figures, a large nuclear size, and hyperchromasia (19). The stage of the disease and the histopathology of the tumor are the two main risk factors. In histopathological evaluation, a WT is classified into two histology groups: (i) good (favorable) and (ii) poor (unfavorable) according to the presence of anaplasia. The presence of anaplasia indicates that the tumor has a 'poor histology'. Anaplasia is seen in $5-10 \%$ of cases. Anaplasia refers to cellular resistance to treatment rather than a tendency towards metastasis or a poor treatment course for the tumor and is considered a predictor of a poor prognosis (20).

The present overall relapse rate was $14 \%$ with an overall post-relapse survival rate of $44 \%$ (20). In our study, the relapse rate was $19.5 \%$. Although the relapse rate was higher than reported in the literature, the post-relapse survival rate was $66 \%$. The most significant risk factor for relapse was unfavorable WT histology. In studies with larger series, the recurrence rate was $15 \%$ in patients with a favorable WT histology and 50\% in patients with anaplastic WT (19) (21). In our study, we found a recurrence rate of $8.1 \%$ in patients with a favorable WT histology and a recurrence rate of $60 \%$ in patients with anaplastic WT.

It has been reported that tumor stage is a critical prognostic factor (22). In our study, of the four patients who did not survive, two had stage III tumors and two had stage IV tumors.

WT most commonly metastasizes to the lungs, regional lymph nodes and liver, and less commonly to the brain and bone (23-25). 80\% of hematogenous metastases occur in the lungs or the liver alone or together with the lungs in $15 \%$ of patients (24). In our study, similar to the literature, we found that metastases of WT cases were most common in the lungs with $76.9 \%$.
Clear cell sarcoma of the kidney (clear cell sarcoma) is the second most common kidney tumor. It is usually seen in boys aged 3-5 years. Metastases are most commonly found in the lungs and bones. In previous studies, it was determined that the 1-10 year surveillance rate was 57$83 \%$. In our study, the 5-year surveillance of three cases with clear cell sarcoma was $100 \%$.

Malignant rhabdoid tumors of the kidney are malignant tumors that are most commonly located in the kidneys and/or brain, and are usually seen in infants and young children, with a frequency of $2 \%$ of all cancer types. A brain tumor is seen together with a kidney tumor. Despite treatment, there is a poor prognosis for his type of tumor: the mortality rate is $80 \%$, and the cure rate is low (3). Similar to the literature, the two rhabdoid tumor cases we detected in our data were seen in children under the age of one in whom brain metastases were detected; the mortality rate was $100 \%$.

Despite its merits, the present study has two main limitations. First, as in all retrospective studies, our study was dependant on secondary data, which may have been subject to biases or errors in collection. Second, the present study was single-centered and featured a short post-op follow-up period.

\section{CONCLUSION}

The results showed that most common renal tumor in childhood was WT, which was similar to the findings in the literature. Surgical procedure appeared to have no effect on survival; the most important survival factors were detecting the existence of rhabdoid tumors and anaplasia histopathologically. Therefore, during the follow-up and treatment of renal tumors in childhood, pathological examination should be of primarary importance and followed up with the pediatric oncologists.

\section{ETHICAL DECLARATION}

Ethics Committee Approval: The study was carried out with the permission of Ankara City Hospital Clinical Researchs Ethics Committee (Date: 10.13.2021, Decision No: E2-21-436).

Informed Consent: Because the study was designed retrospectively, no written informed consent form was obtained from patients.

Referee Evaluation Process: Externally peer-reviewed.

Conflict of Interest Statement: The authors have no conflicts of interest to declare.

Financial Disclosure: The authors declared that this study has received no financial support. 
Author Contributions: All of the authors declare that they have all participated in the design, execution, and analysis of the paper and that they have approved the final version.

\section{REFERENCES}

1. Malkan AD, Loh A, Bahrami A, et al. An approach to renal masses in pediatrics. Pediatrics 2015; 135: 142-58.

2. Kieran K, Ehrlich PF. Current surgical standards of care in Wilms tumor. In Urologic Oncology: Seminars and Original Investigations 2016; 34: 13-23.

3. Saula PW, Hadley GP. Pediatric non-Wilms' renal tumors: a third world experience. World J Surg 2012; 36: 565-72.

4. Ünal E, Yilmaz E, Özcan A, et al. Twenty children with nonWilms renal tumors from a reference center in Central Anatolia, Turkey. Turk J Med Sci 2020; 50: 18-24.

5. Pritchard-Jones K, Dome JS (eds.). Renal Tumors of Childhood: Biology and Therapy, Pediatric Oncology. SpringerVerlag Berlin Heidelberg; 2014. doi:10.1007/978-3-662-44003-2_3.

6. Tan XH, Zhang DY, Liu X, et al. Retrospective analysis to determine outcomes of patients with bilateral Wilms tumor undergoing nephron sparing surgery: 15-year tertiary singleinstitution experience. Pediatr Surg Int 2018; 34: 427-33.

7. Pan C, Cai JY, Xu M, et al. Renal tumor in developing countries: 142 cases from a single institution at Shanghai, China. World J Pediatr 2015; 11: 326-30.

8. Genç B, Özkan MA. Çocukluk çağı böbrek tümörleri. Kanser Gündemi Dergisi 2016; 4: 1-2.

9. Bozlu G, Çıtak EÇ. Evaluation of renal tumors in children. Turk J Urol 2018; 44: 268-73.

10. Miniati D, Gay AN, Parks KV, et al. Imaging accuracy and incidence of Wilms' and non-Wilms' renal tumors in children. J Pediatr Surg 2008; 43: 1301-7.

11. Ward E, DeSantis C, Robbins A, Kohler B, Jemal A. Childhood and adolescent cancer statistics, 2014. CA Cancer J Clin 2014; 64: 83-103.

12. Dumoucel S, Gauthier-Villars M, Stoppa-Lyonnet D, et al. Malformations, genetic abnormalities, and Wilms tumor. Pediatr Blood Cancer 2014; 61: 140-4.

13. Emir S, Kan R, Demir HA, Cakar N, Güler M. Occurrence of Wilms tumor in a child with urofacial (OCHOA) syndrome. Pediatr Hematol Oncol 2011; 28: 616-8.

14. Metzger ML, Dome JS. Current therapy for Wilms' tumor. Oncologist 2005; 10: 815-26.

15. Kembhavi SA, Qureshi S, Vora $T$, et al. Understanding the principles in management of Wilms' tumour: can imaging assist in patient selection? Clin Radiol 2013; 68: 646-53.

16. Venkatramani R, Malogolowkin M, Davidson TB, May W, Sposto R, Mascarenhas L. A phase I study of vincristine, irinotecan, temozolomide and bevacizumab (vitb) in pediatric patients with relapsed solid tumors. PLoS One 2013; 8: e68416.

17. Ritchey ML, Shamberger RC, Haase G, Horwitz J, Bergemann T, Breslow NE. Surgical complications after primary nephrectomy for Wilms' tumor: report from the National Wilms' Tumor Study Group. J Am Coll Surg 2001; 192: 63-8.

18. Mavinkurve-Groothuis AM, van den Heuvel-Eibrink MM, Tytgat GA, et al. Treatment of relapsed Wilms tumour (WT) patients: experience with topotecan. A report from the SIOP Renal Tumour Study Group (RTSG). Pediatr Blood Cancer 2015; 62: 598-602.

19. Spreafico F, Bellani FF. Wilms' tumor: past, present and (possibly) future. Expert Rev Anticancer Ther 2006; 6: 249-58.
20. Cunningham ME, Klug TD, Nuchtern JG, et al. Global Disparities in Wilms Tumor. J Surg Res 2020; 247: 34-51.

21. Lovvorn HN 3rd, Pierce J, Libes J, et al. Kenyan Wilms Tumor Consortium. Genetic and chromosomal alterations in Kenyan Wilms Tumor. Genes Chromosomes Cancer 2015; 54: 702-15.

22. Davidoff AM. Wilms' tumor. Curr Opin Pediatr 2009; 21: 357-64.

23. Berger M, Fernandez-Pineda I, Cabello R, et al. The relationship between the site of metastases and outcome in children with stage IV Wilms tumor: data from 3 European pediatric cancer institutions. J Pediatr Hematol Oncol 2013; 35: 518e24.

24. Verschuur A, Van Tinteren H, Graf N, Bergeron C, Sandstedt B, Kraker J. Treatment of pulmonary metastases in children with stage IV nephroblastoma with risk-based use of pulmonary radiotherapy. J Clin Oncol 2012; 30: 3533-59.

25. Iaboni DSM, Chi YY, Kim Y, Dome JS, Fernandez CV. Outcome of Wilms tumor patients with bone metastasis enrolled on national Wilms tumor studies 1-5: a report from the children's Oncology group. Pediatr Blood Canc 2019; 66: e27430. 